\title{
ESTUDO COMPARATIVO DA POLINIZAÇÃO DE DUAS ESPÉCIES DE IPOMOEA (CONVOLVULACEAE) EM ÁREA ANTROPIZADA NO SEMIÁRIDO BAIANO
}

\author{
Eliane da Silva Anunciação ${ }^{1}$; Miriam Gimenes ${ }^{2}$ \\ 1. Bolsista PIBIC/CNPq, Graduanda em Licenciatura em Ciências Biológicas, Universidade Estadual de Feira de \\ Santana, e-mail: esanunciacao@ hotmail.com \\ 2. Orientadora, Departamento de Ciências Biológicas, Universidade Estadual de Feira de Santana, e-mail: \\ miriagimenes@gmail.com
}

PALAVRAS-CHA VE: polinização; área antropizada; abelhas.

\section{INTRODUÇÃO}

A familia Convolvulaceae possui distribuição cosmopolita incluindo 55 gêneros e 1930 espécies (Judd et al., 2009). Das espécies de Convolvulaceae endêmicas do Brasil, o gênero Ipomoea L. apresenta distribuição geográfica que inclui áreas de caatinga no Nordeste do Brasil (Simão-Bianchini; Ferreira, 2010). Este gênero é o mais amplo da familia Convolvulaceae com aproximadamente 550 espécies (Pacheco-Filho, 2010). Segundo Kiill (1998), as flores do gênero Ipomoea são visitadas geralmente por abelhas, principalmente as dos gêneros Apis, Centris, Ceratina e Euglossa. Devido à importância da familia Convolvulaceae para a biodiversidade do semiárido nordestino, este projeto tem como objetivo geral estudar a polinização de duas espécies sintópicas do gênero Ipomoea que crescem em área do tipo aberto e antropizada, que podem compartilhar os mesmos visitantes florais, com enfoque na eficiência da polinização, tendo em vista adaptações morfológicas, comportamentais e temporais dos visitantes florais.

\section{METODOLOGIA}

O estudo foi realizado bimestralmente de setembro de 2015 a julho de 2016 no Campus da Universidade Estadual de Feira de Santana (UEFS). Durante este tempo foram feitas observações do comportamento dos visitantes florais em duas áreas de aproximadamente $10 \times 10 \mathrm{~m}$, devido à dificuldade da separação dos indivíduos de Ipomoea bahiensis Willd e com quatro indivíduos de Ipomoea carnea subsp. fistulosa Mart. ex Choisy D.F. Austin. Estas observações foram realizadas das 7:00 as 13:00 h durante dois dias da semana. Durante o período descrito acima também foi realizado o teste de eficiência de polinização através de três visitas à flor com os visitantes mais frequentes de ambas espécies I. bahiensis e I. carnea (10). O comportamento de coleta de recurso floral das abelhas mais frequentes foi registrado.

Foi realizado teste de receptividade estigmática através da imersão do estigma das duas espécies de plantas estudadas em peróxido de oxigênio. A análise da morfologia dos visitantes mais frequentes foi realizada através de medidas do tamanho, do comprimento do corpo e da largura intergular utilizando-se os indivíduos que foram coletados com paquímetro digital. Para determinar a biologia reprodutiva das espécies de plantas tratamentos de autopolinização espontânea, autopolinização manual, polinização cruzada (geitonogamia), polinização cruzada e controle (15).

Foram feitos testes de viabilidade e germinação polínica nas flores de I. carnea, no Laboratório de Micromorfologia Vegetal. Para estes testes foram coletadas três flores em três indivíduos diferentes de I. carnea, às 08:00 h. A germinação do pólen in vitro foi feita em meio $\mathrm{BCa}(\mathrm{H} 3 \mathrm{BO} 30.01 \%$ e $\mathrm{Ca}(\mathrm{NO} 3) 2$ 0.03\%) com sacarose a $10 \%$, ágar $0,4 \%$ e pH ajustado para 6,5. 
Foi realizado um mapeamento com os botões de I. carnea, para investigar se os botões das inflorescências apresentavam algum padrão de abertura de I. carnea. Os botões foram marcados com um fragmento de fita vermelha e observados no dia seguinte.

Foram realizadas medidas de comprimento total e largura do tubo das flores, diâmetro da corola e tamanho das estruturas reprodutivas das flores com paquímetro digital com intuito de comparar o tamanho das flores das plantas estudadas com o tamanho dos visitantes florais de I. bahiensis e de I. carnea.

\section{RESULTADOS E DISCUSSÃO}

As flores de I. carnea e I. bahiensis foram visitadas pelo mesmo grupo de abelhas: Melitoma sp., Augochlora sp., Pseudoaugochlora sp., Ancyloscelis sp., Ceratina sp. (crewlla), Apis mellifera, Ptilothrix sp., Xylocopa sp., Trigona spinipes, Euglossa sp.

A grosso modo, os visitantes florais tiveram o comportamento de coleta de recurso semelhante nas duas espécies de planta do estudo, podendo ser divididos em dois grandes grupos. O primeiro grupo formado por abelhas que entravam na flor $\mathrm{e}$ caminhar através da parede do tubo floral para coletar pólen nas anteras. Podendo ser destacadas Melitoma, Pseudoaugochlora, Euglossa, Ceratina sp. (crewella), A. mellifera, T. spinipis e Ptilothrix. O segundo grupo formado por abelhas que entravam nas flores para coletar néctar, podendo ser destacados Xylocopa, A. mellifera, Melitoma e Augochlora. Dessa forma podemos inferir os visitantes florais encontrados no nosso trabalho eram as mesmas as encontradas nos outros estudos relatados na literatura e que possuíam comportamento semelhante (Fidalgo, 1997; Kiill, 1998; Pacheco-Filho, 2010).

O teste de eficiência de polinização realizado com os potenciais polinizadores não gerou nenhum fruto. $\mathrm{O}$ mesmo teste foi realizado para as flores de I. bahiensis, havendo produção de frutos nos experimentos com as visitas de A. mellifera e Melitoma spp. Essas abelhas foram consideradas polinizadores potenciais e I. bahiensis, pois elas tocavam as anteras e o estigma das flores. Araújo (2015) realizou o mesmo teste com $I$. bahiensis e verificou que a maior produção de frutos foi registrado para as visitas de Melitoma spp., seguida por A. mellifera e por Pseudoaugochlora pandora.

No experimento de receptividade estigmática foi verificado que durante todo horário em que o experimento foi realizado o estigma se manteve receptivo. Araújo (2015) realizou o mesmo experimento com as flores de I. bahiensis em uma área do Campus da Universidade Estadual de Feira de Santana (UEFS) e também verificou que o estigma das flores é receptivo o dia todo, porém teria um intervalo com maior formação de bolhas entre 08:00 as 12:00 h.

Os experimentos de biologia reprodutiva realizados em $I$. carnea não geraram produção de frutos. A ausência de frutos no teste em condições naturais (controle) pode ocorrer quando há ausência de visitantes florais na área de estudo. Esta hipótese não foi testada neste trabalho. O resultado dos outros experimentos nesta espécie pode ter ocorrido pelo horário em que foram feitos os experimentos das polinizações manuais, sendo que é colocado na literatura que a elevada temperatura do ar pode causar a desidratação do grão de pólen, tornando-o inviável. Mais experimentos de biologia reprodutiva, e em horários diferentes seriam necessários para obter resultados com relação à formação de frutos. Paz (2011) realizou os mesmos experimentos com as flores de I. carnea no Campus da UEFS e verificou que a espécie é autoincompatível e nos experimentos de controle de exclusão de visitantes noturnos e diurnos e sem exclusão de visitantes que a produção de fruto foi similar em todos esses experimentos (em torno de $50 \%$ de sucesso na produção de frutos). 
Os experimentos de biologia reprodutiva realizados com I. bahiensis mostrou que a produção de frutos no experimento de polinização cruzada $(66,6 \%)$ foi maior do que por autopolinização $(6,6 \%)$. O resultado do experimento de polinização cruzada nesta espécie está bem próximo ao experimento em condições naturais, indicando que, provavelmente, os polinizadores desta espécie estavam presentes na área de estudo. A autogamia foi observada nos resultados dos experimentos de autopolinização manual e geitonogamia $(33,3 \%)$ indicando que está planta possui autogamia mista, podendo ou não produzir frutos. Araújo (2015), também verificou uma maior produção de frutos nos experimento de polinização cruzada do que nos de autopolinização, demonstrando que a transferência de pólen de flores diferentes de uma mesma planta, ou de plantas diferentes produzem uma maior quantidade de fruto, sendo necessário então, a presença dos visitantes florais para que aconteça a polinização dessa planta

A maior taxa de viabilidade do pólen para o experimento submetido à silica foi de $99 \%$ e a maior taxa para os que não foram submetidos à sîlica foi de $98 \%$, demonstrando que a maioria dos grãos de pólen estavam altamente viáveis. $\mathrm{O}$ experimento de germinação teve a taxa de germinação de pólen muito baixa. O teste em que o pólen ficou exposto a silica teve a maior taxa germinativa $(21 \%)$ e o pólen que não foi exposto teve a maior taxa de germinação (14\%). O experimento de polinização cruzada (xenogamia) não houve produção de frutos. Kill; Ranga (2003), fizeram um trabalho de ecologia da polinização de Ipomoea asarifolia na região semiárida de Pernambuco, onde realizaram testes de viabilidade de pólen e de crescimento do tubo polínico e viram que $94,4 \%$ dos grãos de pólen estavam altamente viáveis.

O mapeamento dos botões mostrou que a abertura dos botões ocorriam em diferentes horários na mesma inflorescência ou no mesmo ramo floral, nas mesmas inflorescências havia flores abrindo nos 3 diferentes horários. A partir deste teste podemos inferir que a abertura das flores ocorre aleatoriamente entre os indivíduos de $I$. carnea e que em qualquer ramo da planta e na mesma inflorescência pode ocorrer o mesmo evento.

$\mathrm{O}$ resultado das medidas florais mostraram que as flores de $I$. carnea é maior do que o tamanho dos flores de I. bahiensis. O tamanho dos visitantes florais está intrinsecamente relacionado com o tamanho das flores. $\mathrm{O}$ diâmetro do tubo das flores das duas plantas selecionou os polinizadores potenciais, sendo assim as abelhas do nosso estudo que possuíam o tamanho médio eram as potenciais polinizadoras, pois conseguiam contatar as estruturas reprodutivas. As abelhas com o tamanho grande não conseguiam entrar no tubo floral, sendo consideradas não potenciais para realizar a polinização das plantas desse estudo (Tabela1).

Tabela 1: Tamanho e comportamento dos visitantes florais de I. bahiensis e I. carnea.

\begin{tabular}{lcccc}
\hline Espécie & Comprimento & $\begin{array}{l}\text { Largura entre } \\
\text { tégulas }\end{array}$ & Comportamento & Porte \\
\hline $\begin{array}{l}\text { HYMENOPTERA } \\
\text { Apidae }\end{array}$ & & & & \\
$\begin{array}{l}\text { Melitoma sp. } \\
\text { Ancyloceles }\end{array}$ & 8,67 & 2,49 & Pó1/Néc & MI \\
$\begin{array}{l}\text { apiformes } \\
\text { Euglossa sp. }\end{array}$ & 5,47 & 1,44 & Pól & P \\
$\begin{array}{l}\text { Ceratina sp. } \\
\text { (crewella) }\end{array}$ & 8,23 & 3,05 & Pól & MR \\
$\begin{array}{l}\text { Apis mellifera } \\
\text { Ptilothrix sp. }\end{array}$ & 5,53 & 1,17 & & Pól \\
Xylocopa sp. & 9,34 & 2,36 & Pó1/Néc & MI \\
& 10,15 & 3,5 & Pól & MP \\
\end{tabular}




\section{Halictidae}

Augochlora sp.

Pól/Néc

Legenda: Porte: $\mathrm{GR}=$ grande robusto, $\mathrm{MR}=$ médio robusto, $\mathrm{MI}=$ médio intermediário, $\mathrm{MP}$ $=$ médio pequeno, $\mathrm{P}=$ pequeno. Comportamento: $\mathrm{Pól}=$ pólen, Néc= néctar.

\section{CONSIDERAÇÕES FINAIS}

As duas espécies de plantas possuem a mesma fauna de visitantes florais. $\mathrm{O}$ estigma das duas plantas fica receptivo durante toda a abertura floral aumentando as chances de ocorrência da polinização. A abertura dos botões podem ocorrer em horários diferentes na mesma inflorescência e ramo floral. As medidas das flores de ambas espécies e visitantes está intrinsecamente relacionados, no qual ocorre um "encaixe" entre a flor e visitante ocasionando na polinização. A maioria dos grãos de pólen estavam altamente viáveis, no entanto a taxa de germinação do pólen foi baixa o que indica que o meio e horário em que foi realizado o experimento não foi ideal para a germinação do pólen. Além disso, ambas as flores possuem caráter ornamental, dando destaque para $I$. bahiensis que ocorre naturalmente no semiárido baiano como uma alternativa para o uso em jardins e cercas-vivas.

\section{REFÊNCIAS}

ARAÚJO, L.S. 2015. Padrões temporais da interação entre Ipomoea bahiensis (Convolvulaceae) e seus visitantes florais. Universidade Estadual de Feira de Santana, Dissertação.

FIDALGO, A.O. 1997. Ecologia floral de duas espécies invasoras de Ipomoea (Convolvulaceae). Dissertação de Mestrado. Instituto de Biologia da Universidade Estadual de Campinas. São Paulo, p. 99.

JUDD, W.S.; CAMPBELL, C.S.; KELlOGG, E.A.; STEVENS, P.F.; DONOGHUE, M.J. 2009. Sistemática vegetal: um enfoque filogenético. $3^{\mathrm{a}}$ ed. Porto Alegre: Artmed, p. $462-463$.

KIILL, L.H.P. 1998. Biologia da polinização e reprodutiva de sete espécies de Convolvulaceae na caatinga do Sertão de Pernambuco. Tese de doutorado, Universidade Estadual de Campinas, Tese.

Kill, L.H.P.; RANGA, N.T. (2003). Ecologia da polinização de Ipomoea asarifolia (Ders.) Roem. \& Schult. (Convolvulaceae) na região semiárida de Pernambuco. Acta Botânica Brasilia, 17 (3): 355-362.

PACHECO-FILHO, A.J.S. 2010. Ecologia da polinização e biologia reprodutiva de Ipomoea bahiensis Willd. no semiárido brasileiro. Universidade Federal do Ceará, Dissertação.

PAZ, J.R.L. 2011. Biologia floral e polinização diurna e noturna de Ipomoea carnea subsp. fistulosa (Mart. ex Choisy) D.F. Austin (Convolvulaceae) em uma área antropizada no semiárido da Bahia, Brasil. Universidade Estadual de Feira de Santana, Dissertação.

SIMÃO-BIANCHINI, R.; FERREIRA, P.P.A. 2010. Convolvulaceae in Lista de Espécies da Flora do Brasil. Jardim Botânico do Rio de Janeiro. 